Journal of Social Sciences 6 (3): 365-368, 2010

ISSN 1549-3652

(C) 2010 Science Publications

\title{
The Role of Molam in Solving Social Problems
}

\author{
Sitthisak Champadaeng \\ The Research Institute of North Eastern Arts and Culture, \\ Mahasarakham University, Maha Sarakham, 44000, Thailand
}

\begin{abstract}
Problem statement: Mo-lam is the most popular Isan Local Song. Its rhythm and message influenced people's feeling and thought. The objectives of this research were to study: (1) the moving force in using the media of Mo-lam for solving social problem, (2) the role of Mo-lam and social problem solving and (3) the effect of campaign with the sharing in approach and behavior of receiver in Klon-lam media. Approach: The research area in Isan Region included Maha Sarakam Province, Roi-Ed Province, Ubon Rachatani Province, Khon Kaen Province, Chiaypume Province, Udon Tani Province, Nakon Phanom Province, an Mookdahan Province. The samples providing information were 105 persons selected by interviewing and Participant Observation. Data were analyzed in characteristic. Then, the findings were presented in descriptive analysis. Results: The research findings found that: (1) the moving force for Mo-lam Media Use, was caused by the rapid Isan Social and Cultural Changes after the Second World War owing to the economic developmental policy as specified by the public sector As a result, Isan society faced trouble in social, economic and political aspects. There were migration and moving to work in big sized cities, lack of educational management as well as basic public health service, (2) the roles of Mo-lam in solving social problems were as follows: Klon-lam campaigning in the enhancement for national security, was composed, lam against the communist doctrine and enhancing the democracy, campaigning for people to be interested in Education as well as controlling the population number, infectious disease and supporting the exercise. In solving the environmental problems, the natural resources were campaigned and the waste in community was got rid of, the prevention and treatment for drug addiction problem was campaigned, (3) the effect of campaign and changes in viewpoint and behavior of Klon Lam Receivers, in political and governmental security as a part of the elimination the communist doctrine from Thailand. In public health, the population control was campaigned by informing people to understand the birth control and family planning. In hygiene, people accesses the health care technique more. Besides, in prevention and treatment for drug addiction, it was partly effective. The legal measure needed to be used in aligned with. Conclusion/Recommendations: This research could be used as a guidelines for developing and enhancing the roles of local artists as well as using benefit from local media for correcting and developing the locality with stability.
\end{abstract}

Key words: Role, molam, solving, social problems

\section{INTRODUCTION}

Mo-lam involved in mechanism of the government policy system. The success as a good media might be because Mo-lam used the composed language with impressive content and material. Furthermore, most of audiences understood the communicated language which was a common culture of Isan People. In the present, Mo-lam is not only an entertainment providing joyfulness but also collaborate with the public organization and work unit as well as political parties in solving social problems continuously such as the problem of understanding in democracy, moral precept problem, education problem, hygiene problem and drug addiction problem.
According to the survey of basic information, it was known that Mo-lam was used as a media in problem solving as well as public relation for public policy. It was aimed to people in obtaining knowledge and understanding in the material to be communicated. In general, there were both of single artist and team artist. Their role was to produce media enhancing exercise instead of using the western song with unrelated content with locality. The public health of Roi-Ed Province was the project owner for distributing tape, compact disc, VCD, for the health center throughout Roi-Ed Province. Now, it is during Mo-lam Implementation including role in providing information in tourism. The project owner is the Tourism Organization of Thailand by assigning the poetry 
composing for describing the traveling sources which would be broadcasted throughout the country. Moreover, there were other artists with name list existing in area of artist research playing role in many aspects as well.

In the present, although the traditional Lam was less popular, there was continuous development of pattern in presentation. The content and material were changed according to the audiences' preference from external factor as major factor. Another value of artists was the role in solving problem as well as enhancing social stability as a source of knowledge which might be used for analyzing Isan Social Problem further.

\section{MATERIALS AND METHODS}

The study area was the North Eastern of Thailand including Maha Sarakam Province, Roi-ed Province, Ubon Rachatani Province, Khon Kaen Province, Chaiyapume Province, Udon Tani Province, Nakon Phanom Province and Mookdahan Province. Qualitative Method was used in this research by collecting data from samples as Purposive Sampling, including 3 groups of population: 24 persons from public sector and private sector, 70 audiences in the area using Klon-lam in the campaign and 11 famous Mo-lams, total of 105 persons. The instruments using for collecting data, consisted of the Interview Form, the Observation Form and Focus Group Discussion. Data were investigated by Triangulation Technique according to the issues in the research study and presented in descriptive analysis.

\section{RESULTS}

The research findings were as follows:

- The moving force for using Klon-lam was caused by the rapid Isan Social and Cultural Changes owing to the specified policy in National Economic and Social Development Plan, Issue 1-4, started using after World War 2. Consequently, Isan Society was in trouble in social, economic and political aspects. There was a high rate of population growth causing many impacts such as the land for earning one's living, migration and moving, occupation, educational service, basic public health service. So, it was a need for emergent development with quickly effective. Later on, the problems were more clearly reflected in various aspects. The first aspect: population, before specifying in policy of population in Thailand, it was no limit. Therefore, National Economic and Developmental Plan, Issue 3, had policy in controlling the population birth rate. The second issue: national security, Thailand faced problems alleviating its security during the first session of Communist Doctrine especially in Isan Region, it was more serious problem than the other regions. The third issue: natural resource problem as basic major factor of Isan People on their living was lowered down. The fourth aspect: hygiene in Isan Locality, Isan people still had hygiene problem owing to their food eating habit as well as simple residence. Finally, there was a problem of disease and illness

- There were many Mo-lam's roles in solving social problem. The first role, the role of national security, was played by opposing the Communist Doctrine and enhancing the democracy. The second role, the education, artists composed Klonlam and Lam campaigning people to be interested in education. The third role, in public health, there was a campaign for controlling population number, infectious disease and enhancing the exercise. The fourth role, environmental problem solving, there was a campaign for conserving the natural resources as well as getting rid of the filthy in community. The fifth role, prevention and treatment for solving drug addiction problem, the campaign for knowing the danger of every kind of drug addiction, was performed

- There were many effects of campaign and changes in viewpoint and behavior of receivers in Klonlam. The first one, National Political and Government Security, communist doctrine, was eradicated from Thai Society. The second one, public health, the result in population, its number was decreased. The citizen understood in birth control and family planning. In hygiene, the citizen accessed the health care more. Isan people started understanding the hygiene in living. The third one, natural resource problem, there was more enthusiastic. The fourth one, prevention and treatment in drug addiction problem, there was partially effective. The lawful measure needed to be used in aligned with it. Every aspect was changed in a good way after using Klon-lam in the campaign

\section{DISCUSSION}

According to research findings, they were discussed as follows:

- Mo-lam was a regular wisdom in each locality as a readymade formula being able to be adapted with 
human's lifestyle in each society. It wasn't occur in the present keeping pace with situation. But, those kinds of knowledge were filtered and transferred throughout the time. The fact from some kinds of phenomena was new and the problems could be solved by human beings. It didn't mean that the human beings didn't use their former experience. Therefore, the application in existed wisdom was an important thing. It was supported by Na-ta-Lang (2007) approach in wisdom by suggesting guidelines that the wisdom refers to developed and descended knowledge, thought, belief, ability and clearness which people obtain from their collected experience in adaptation and living in ecology system or natural environment as well as social and cultural environment. The wisdom is knowledge, thought, belief, ability, clearness resulting from the intellectual use in adjusting oneself with different situations or changing for creating the usefulness or solving problem in the social and cultural environment and context of those groups of people

- The selected Mo-lam for studying, still played its role in enhancing the local art and culture by various guidelines, for example, participation in seminar for providing knowledge in different institutes, opening school for teaching Mo-lam subject. Mo-lam performed duty as a leader of thought for people in locality as well as coordinator between the government and people, people and people. Mo-lam who played role in politic, often be a good wisdom, high competency, famous, accepted in society and locality, used to be successful in earning living as M0-lam-klon before, as a master of Mo-lam-klon. Besides, Mo-lam-klon also worked as a communicator in policy for different work units of government which were work units involving with the mass and national development including: the work unit for public relation, education, government, public health, national power, agriculture, irrigation. For dissemination, was performed by campaigning, persuasion, providing knowledge in politic as well as other government policies. It was supported by Bootmansri (1995) findings found that there were many aspects of reflected picture of Isan Society from Klon-lam Mo-lam Ken Dalao, for example, the politic and governmental aspect reflecting the loyalty to the King's Institute and political incidences. In economic aspect, Isan Farners were treated unfair by mediators. In education aspect, it reflected the parents' preaching since they paid attention to their children's behavior to be interested in the education. Dharmawat (2007) conducted research in wisdom of Mo-lam Ek.

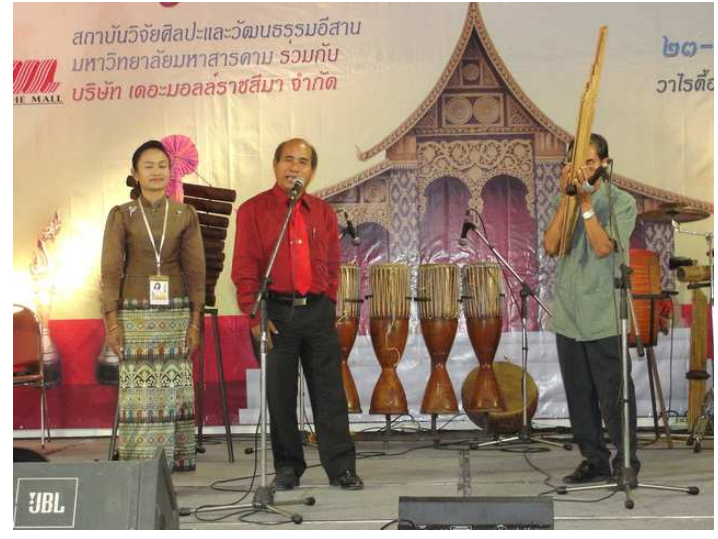

Fig. 1: Photograph of Molam Klon Singer in Isan

The prosperous in the past and problem of Mo-lam in the present, found that now Lam-klon was less popular. The new dominant role of Lam-klon show was the lam for providing knowledge and information for Isan People regarding to social problem, government policy, emergent policy for people and people's need to the governmental work unit

In public health aspect, it was supported by PrasertThaijaroen (2001) study the public health. The research findings found that the provision of knowledge in self care for the aging people with diabetes by using Klonlam media, was a good technique since Klon-lam was a symbolic model with identity by using local language of Northeastern Region. So, it was easily understood especially in singing together with music which was sweet-sounding as Kan (Thai reed mouth-organ), the type of verse was rhymed, its content was easy to remember (Fig. 1). The group obtained knowledge by using supplementary Klon-lam. After receiving knowledge for 2 weeks, they practiced better in self care than before obtaining knowledge. The patients' practice in self care was improved. Their health was better.

\section{CONCLUSION}

- The usage of local media should be the most appropriately and efficiently extended since in the former time, different organizations using benefit from Mo-lam Artists didn't take care the media production. There were only the artist sector volunteering to play their role in solving social problems. So, it was interested in by the organizations. According to the important, the government or work units using benefit from media 
should have their planning for determining the efficient media use to be relevant to the occurred problems. Besides, they should support in the following aspects

- For the Klon-lam composers, inn the present, they were the scholars experiencing Buddhism System while they were ordaining. They studied different Dharma Discipline as well as poetries. After leaving their monkhood to be laities, they might be Mo-lam while composing the poetry. If this generation was gone, there would be no quality poetry composers. Therefore, there should be a study collecting the existed names as a basic information. In addition, the workshop should be held by demonstrating the different kinds of poetry. The total of composed verse should be gathered for printing the textbook in recording tape, slide, moving picture as evidence for the study further

- For low quality according to the study, found that the new artists had low quality if many aspects, for in stance, the ability in lam, the rhythm of lam as the uttering of rhythm, low or no and no standpoint of artist. As a result, the school or institute teaching Mo-lam should be established

\section{REFERENCES}

Bootmansri, O., 1995. Reflected Picture of Isan society from Klon-Lam of Mo-Lam Ken da-Lao. Master of Education Thesis, Mahasarakam University.

Dharmawat, J., 2007. Mo-lam-ek Wisdom: The Brilliant of the Past and Problem of mo-lam, in the Present. 1st Edn., Mahasarakam University, Mahasarakam, ISBN: 9749028635, pp: 528.

Na-ta-Lang, E., 2007. Isan Wisdom. 2nd Edn., Wisdom Foundation, Bangkok, ISBN: 974-272-386-9, pp: 115.

Prasert-Thaijaroen, A., 2001. The effect of provided knowledge for heal care in aging patient by using supplementary Mo-lam. Master of Nursing Thesis, Burapa University. 